\title{
Cuerpo extraño como causa de apendicitis aguda complicada
}

\author{
Foreign body as a cause of complicated acute appendicitis \\ Jorge Luis Vélez-Bernal ${ }^{1} \mathbb{D}$, Cristina Estefanía González-Díaz² $\mathbb{D}$, \\ Leidy Dayana Agudelo Jiménez 1 (D)
}

1 Médico, especialista en Cirugía general, Hospital Central de la Policía, Bogotá, D.C., Colombia.

2 Médico general, Hospital Central de la Policía, Bogotá, D.C., Colombia.

\section{Resumen}

La apendicitis aguda es una de las patologías más comunes en el ámbito hospitalario. Las formas complicadas pueden ser causadas por objetos puntigudos, afilados, delgados o alargados, ingeridos de forma accidental, y representan una causa inusual con una prevalencia del $0,0005 \%$.

Palabras clave: apendicitis aguda; complicada; perforación; cuerpo extraño; abdomen agudo; laparoscopia.

\begin{abstract}
Acute appendicitis is one of the most common pathologies in the hospital setting. The complicated forms can be caused by pointed, sharp, thin or elongated objects, accidentally ingested, and represent an unusual cause with a prevalence of $0.0005 \%$.
\end{abstract}

Keywords: acute appendicitis; complicated; perforation; foreign body; acute abdomen; laparoscopy.

\section{Introducción}

La apendicitis aguda es una patología que se presenta en todos los grupos etarios, con una mayor incidencia entre los 11 y 13 años de edad ${ }^{1}$. La ingesta de cuerpos extraños es algo inusual que puede suceder en el 0,0005 \% de la población, y sus complicaciones son menos comunes, con una tasa de perforación extremadamente baja que puede ocurrir en cualquier parte del tracto gastro- intestinal, especialmente en áreas de angulación o estrechamiento como el píloro, la zona fija del ligamento de Treitz, el íleon distal a nivel de la válvula ileo-cecal y la unión recto sigmoidea ${ }^{2}$.

\section{Presentación del caso}

Paciente de 65 años con dolor abdominal tipo cólico localizado en la región inguinal derecha, irradiado al flanco y región lumbar ipsilateral. Se

Fecha de recibido: 17/07/2021 - Fecha de aceptación: 29/07/2021 - Publicación en línea: 09/011/2021

Correspondencia: Cristina Estefanía González-Díaz, Carrera 59 \# 26-21, Bogotá, D.C., Colombia. Teléfono: +57 3168734654

Correo electrónico: jvelez_bernal0406@hotmail.com

Citar como: Vélez-Bernal JL, González-Díaz CE, Agudelo Jiménez LD.Cuerpo extraño como causa de apendicitis aguda complicada. Rev Colomb Cir. 2022;37:139-41. https://doi.org/10.30944/20117582.987

Este es un artículo de acceso abierto bajo una Licencia Creative Commons - BY-NC-ND https://creativecommons.org/licenses/by-nc-nd/4.0/deed.es 
realizó una tomografía computarizada contrastada observando un marcado engrosamiento del apéndice cecal, perdida de su configuración y una colección heterogénea multiloculada con una imagen hiperdensa lineal de aproximadamente 18 $\mathrm{mm}$ en su interior, sugestiva de cuerpo extraño, hallazgos compatibles con apendicitis aguda, perforación contenida y formación de absceso periapendicular (figura 1).

Se realizó apendicectomía por laparoscopia encontrando el apéndice cecal emplastronado, localizado por debajo del íleon distal, con un absceso purulento asociado a perforación apendicular en su tercio medio, donde se encontró un fragmento de hueso de pollo (figura 2).

\section{Discusión}

La perforación del tracto digestivo por cuerpos extraños en cualquier segmento intestinal es rara y ocurre en menos del $1 \%$ de los pacientes que los ingieren ${ }^{2}$. El íleon terminal es el sitio más común de perforación, en el $73 \%$ de los casos, seguido del asa en $\mathrm{C}$ duodenal ${ }^{3}$. Se desconoce la incidencia de apendicitis aguda complicada perforada, siendo la incidencia de todos los cuerpos extraños en el apéndice cecal entre el 0,005 \% y el 0,113 \% ${ }^{3,4}$.

La obstrucción causada por el cuerpo extraño en la luz apendicular, desencadena un proceso inflamatorio característico de la apendicitis y, además, puede causar su perforación ${ }^{4}$. Los cuerpos extraños que salen de la luz intestinal pueden migrar produciendo entidades clínicas como abscesos hepáticos, impactarse en la superficie anterior del epiplón mayor y causar abscesos o efecto de masa a este nivel confundiéndose con neoplasias, también pueden atravesar la vejiga, causando fistulas, o la pared abdominal anterior, saliendo a traves de la piel ${ }^{4}$.

En cuanto a las imágenes diagnosticas se considera que la tomografía computarizada es el método de elección para identificar cuerpos extraños ingeridos, teniendo como desventaja

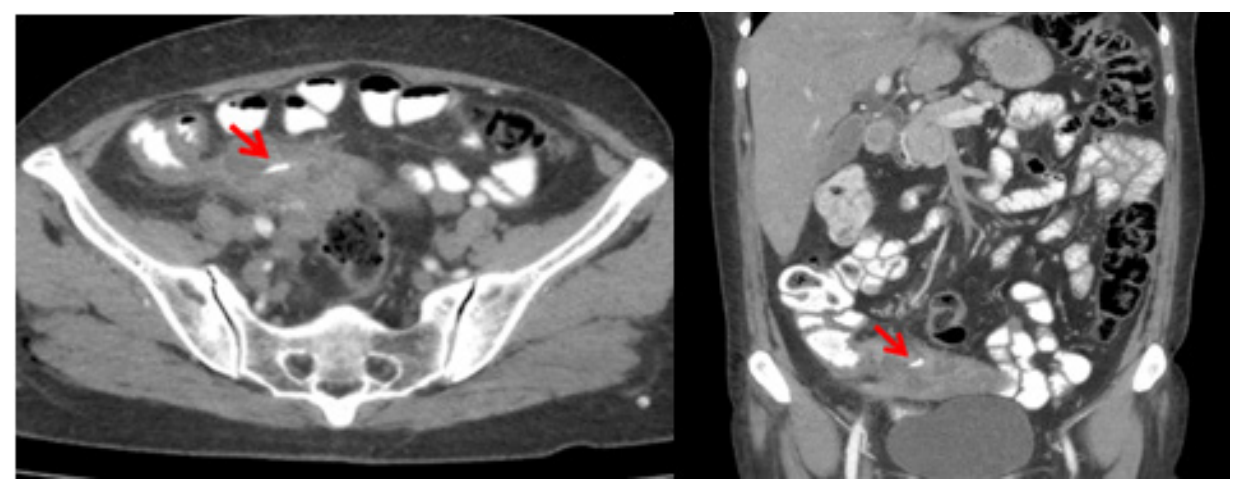

Figura 1. Tomografia computarizada de abdomen con contraste, la flecha señala el cuerpo extraño
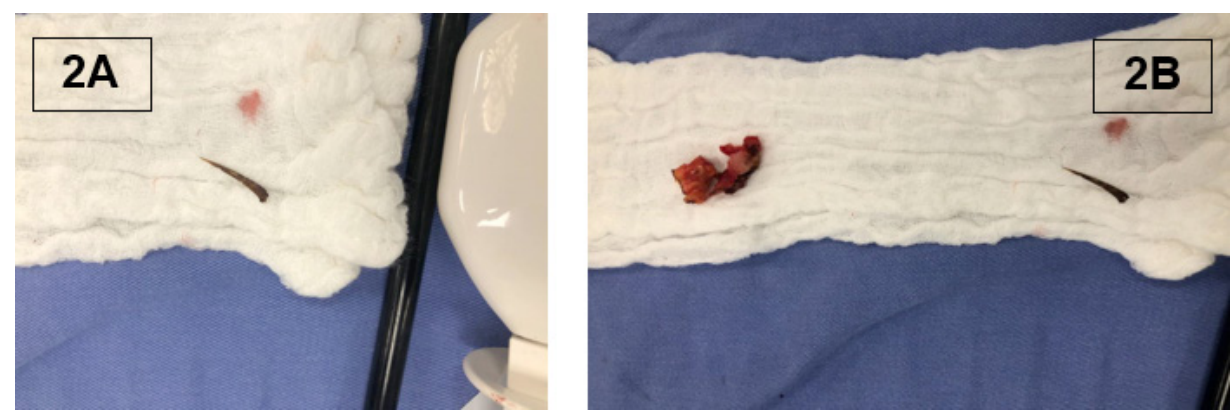

Figura 2. A cuerpo extraño identificado en apéndice cecal. B apéndice cecal y cuerpo extraño. 
que se requieren cortes tomográficos finos y una minuciosa observación del tracto gastrointestinal buscando el cuerpo extraño, en especial en las zonas de angulación y mayor riesgo de perforación, como la unión ileocecal y recto-sigmoidea, o dentro de un saco herniario, un divertículo de Meckel o el apéndice cecal ${ }^{5}$.

\section{Conclusión}

Aunque los cuerpos extraños ingeridos usualmente atraviesan el tracto digestivo sin provocar perforaciones o complicaciones secundarias, en ciertas oportunidades pueden causar apendicitis aguda complicada con una perforación secundaria.

En las imágenes diagnosticas se debe hacer una búsqueda minuciosa de dichos objetos, para definir el manejo quirúrgico, evitando posibles complicaciones asociadas.

\section{Cumplimientos de normas éticas}

Consentimiento informado: Se obtuvo el consentimiento informado para la publicación de este caso por parte del paciente.

Conflictos de interés: Los autores declaran no tener conflictos de interés en la elaboración del presente artículo.

Financiación: Por los autores.

\section{Contribución de los autores}

Concepción y diseño del estudio: Jorge Luis Vélez-Bernal, Cristina Estefanía González-Díaz, Leidy Dayana AgudeloJiménez.
Adquisición de datos: Jorge Luis Vélez-Bernal, Cristina Estefanía González-Díaz, Leidy Dayana Agudelo-Jiménez.

Análisis e interpretación de datos: Jorge Luis Vélez-Bernal, Cristina Estefanía González-Díaz, Leidy Dayana AgudeloJiménez.

Redacción del manuscrito: Jorge Luis Vélez-Bernal, Cristina Estefanía González-Díaz, Leidy Dayana AgudeloJiménez.

Revisión crítica: Jorge Luis Vélez-Bernal, Cristina Estefanía González-Díaz, Leidy Dayana Agudelo-Jiménez.

\section{Referencias}

1. Di Saverio S, Podda M, De Simone B, Ceresoli M, Augustin G, Gori A, et al. Diagnosis and treatment of acute appendicitis: 2020 update of the WSES Jerusalem guidelines. World J Emerg Surg. 2020;15:27. https://doi.org/10.1186/s13017-020-00306-3

2. Chiu JJ, Chen TL, Zhan YL. Perforation of the transverse colon by a fish bone: a case report. The Journal of Emergency Medicine. 2009;36:345-7.

https://doi.org/10.1016/j.jemermed.2007.11.007

3. Costa-Almeida CE, Rainho R, Gouveia A. Codfish may cause acute abdomen. Int J Surg Case Rep. 2013;4:969-71. https://doi.org/10.1016/j.ijscr.2013.08.009

4. Choi Y, Kim G, Shim C, Kim D, Kim D. Peritonitis with small bowel perforation caused by a fish bone in a healthy patient. World J Gastroenterol. 2014;20:1626-9. https://doi.org/10.3748/wjg.v20.i6.1626

5. Barragán C, Rueda JD, Espitia E, Uriza LF, Rosselli D. Perforación intestinal por espina de pescado, revisión de la literatura científica y presentación de dos casos. Rev Colomb Cir. 2012;27:79-84. 